\title{
A STUDY IN MAN OF CEREBRAL BLOOD FLOW AND CEREBRAL GLUCOSE, LACTATE AND PYRUVATE METABOLISM BEFORE AND AFTER EATING*
}

\author{
By GEORGE G. ROWE, GEORGE M. MAXWELL, CESAR A. CASTILLO, \\ D. J. FREEMAN AND CHARLES W. CRUMPTON \\ (From the Departments of Medicine and Cardiopulmonary Research Laboratory of the Uni- \\ versity of Wisconsin, Madison, Wis.)
}

(Submitted for publication June 30, 1959; accepted July 17, 1959)

It has been shown that subjective feelings of hunger (1) and even objective phenomena such as gastric hunger contractions (2) can be correlated with a decreased arteriovenous glucose difference across the forearm. This decrease in arteriovenous difference of glucose was thought to indicate a decreased rate of glucose utilization by peripheral tissues and its role in hunger regulation has recently been reviewed by Mayer $(3,4)$. Since the brain is particularly dependent on glucose for metabolism it would be of interest to determine its response to the fasting state and the ingestion of a test meal. If, in the fasting state, such decreased utilization of glucose occurs in the brain as does peripherally, it would be of interest to know what other carbohydrate substances are utilized and particularly whether or not variation in the amount of glucose taken up by the cerebral tissue is related to the sensation of hunger.

\section{MATERIAL AND METHODS}

Eight subjects were studied after a 14 hour period of fasting. The patients were selected from the general hospital wards and although they presented various forms of disease (rheumatic heart disease, hypertensive heart disease and anxiety tension states) they had no known intracranial disease and were of normal body weight. In some subjects a cardiac catheter was advanced through the left antecubital vein, the left internal jugular vein and into the jugular bulb. In others the jugular bulb was punctured percutaneously. The catheter or needle was then attached to a manifold to permit rapid sampling. A Cournand needle was placed in a peripheral artery and attached by plastic tubing to a heparin filled manifold for rapid sampling and to a strain gage for pressure recording by way of a Sanborn Poly-Viso. Mean pressures were determined by electrical integration of the

* This research was supported in part by grants from the Wisconsin Heart Association, the National Heart Institute of the United States Public Health Service, and the Wisconsin Alumni Research Foundation. pressure curve. Arterial and internal jugular venous blood content of glucose, lactate and pyruvate were determined, respectively, by the methods of Folin and Malmros (5), Friedemann and Haugen (6), and Barker and Summerson (7). Arterial and cerebral venous blood specimens were analyzed for oxygen and carbon dioxide content by the Van Slyke-Neill manometric technique. Cerebral blood flow was determined by the nitrous oxide method of Kety and Schmidt (8).

In each subject cerebral blood flow was determined in the fasting state as were the glucose, lactate and pyruvate in the arterial and internal jugular venous blood. The subject was then fed a standard breakfast consisting of two slices of toast (each covered by one pat of butter), a glass of milk, and a small glass of orange juice containing one heaping teaspoonful of sugar. This meal was estimated to contain approximately $60 \mathrm{Gm}$. carbohydrate, $15 \mathrm{Gm}$. protein, and $20 \mathrm{Gm}$. fat. Determinations of glucose, lactate and pyruvate were made in the arterial and internal jugular venous blood at intervals of $15,30,45$ and 60 minutes after completion of this meal. Cerebral blood flow was determined again between 30 and 45 minutes after the test meal.

Calculation of cerebral consumption of glucose, lactate and pyruvate in the control period was done by multiplying the arteriovenous differences by the control cerebral flow. Since the 15 minute determination of these substances was drawn halfway between the two determinations of cerebral blood flow, the average of these two observations was used for calculating glucose consumption at this time. The calculation of carbohydrate consumption at 30, 45 and 60 minutes was done assuming the cerebral blood flow had remained the same at each of these periods, and that the flow at each interval was that which was measured between 30 and 45 minutes after the consumption of food. Errors introduced by these assumptions and averages should be small, since there was so little change in the blood flow between the first and second determinations.

\section{RESULTS}

Results of this study are summarized in Tables I and II. It will be noted that there were no significant changes in cerebral blood flow, vascular 
resistance, oxygen consumption or respiratory quotient. Peripheral arterial blood pressure, pulse rate, hemoglobin, hematocrit and arteriovenous difference for oxygen and carbon dioxide were also remarkably stable.

Although there was a considerable increase in the arterial level of glucose, the internal jugular glucose content increased also, so that the change in the arteriovenous difference remained small. During the time when the arterial glucose level was rising, the arteriovenous difference increased transiently. As the peak of the curve was reached the arteriovenous difference returned to normal and then as the arterial level began to fall the arteriovenous difference narrowed transiently. Finally, at the end of the study, it again returned to the control state. (See Figure 1.) The calculated glucose consumption increased somewhat but not significantly at 15 minutes, and at 45 minutes was less than during the control observations $(p<$ 0.05 ), even though the blood sugar content remained high at this time compared to the control observations. The arteriovenous difference for lactate and pyruvate indicated that in the fasting state the brain gave up both of these substances to the blood stream. After feeding, the blood level of both of these materials increased and they were
TABLE I

Cerebral hemodynamic observations before and after eating

\begin{tabular}{|c|c|c|}
\hline & Before & After \\
\hline $\begin{array}{l}\text { Mean arterial blood pressure } \\
(\mathrm{mm} . \mathrm{Hg})\end{array}$ & $92 \pm 16^{*}$ & $90 \pm 17$ \\
\hline $\begin{array}{l}\text { Arterial oxygen content } \\
(\mathrm{ml} . / 100 \mathrm{ml} . \text { of blood })\end{array}$ & $16.9 \pm 1.5$ & $17.0 \pm 1.5$ \\
\hline $\begin{array}{l}\text { Arterial-internal jugular } \mathrm{O}_{2} \\
\text { difference (volumes \%) }\end{array}$ & $6.5 \pm 1.8$ & $6.5 \pm 1.5$ \\
\hline $\begin{array}{l}\text { Cerebral blood flow } \\
\text { (ml./100 Gm. brain/min.) }\end{array}$ & $52 \pm 12$ & $55 \pm 14$ \\
\hline $\begin{array}{l}\text { Cerebral oxygen consumption } \\
(\mathrm{ml} . / 100 \mathrm{Gm} . / \mathrm{min} .)\end{array}$ & $3.3 \pm 0.6$ & $3.5 \pm 0.7$ \\
\hline Cerebral respiratory quotient & $0.98 \pm 0.06$ & $0.96 \pm 0.0$ \\
\hline
\end{tabular}

* Standard deviation (in each case).

taken up by the brain. The increased lactate uptake proved transitory (see Table II) with neither extraction $(r=0.20)$ nor calculated consumption $(r=0.21)$ significantly related to the arterial lactate level. The pyruvate extraction and calculated consumption remained increased throughout the period of study and were correlated positively with the arterial pyruvate level $(r=0.70, p<$ 0.001 and $r=0.68, p<0.001$, respectively). No difference was apparent between those who stated that they were hungry and those who were not.

TABLE II

Blood carbohydrate changes across the brain before and after eating

\begin{tabular}{|c|c|c|c|c|c|}
\hline & Control & 15 min. & $30 \mathrm{~min}$. & $45 \mathrm{~min}$. & $60 \mathrm{~min}$. \\
\hline $\begin{array}{l}\text { Arterial glucose content } \\
\text { (mg. } / 100 \mathrm{ml} .)\end{array}$ & $106 \pm 7.1^{*}$ & $144 \pm 19.8$ & $150 \pm 18.8$ & $143 \pm 23.3$ & $137 \pm 18.0$ \\
\hline $\begin{array}{l}\text { Cerebral A-V† glucose difference } \\
\text { (mg. } / 100 \mathrm{ml} \text {. blood) }\end{array}$ & $11 \pm 2.3$ & $13 \pm 2.5$ & $10 \pm 2.7$ & $8 \pm 4.6$ & $10 \pm 2.7$ \\
\hline $\begin{array}{l}\text { Cerebral glucose extraction } \\
(\mathrm{mg} . / 100 \mathrm{Gm} . \text { brain } / \mathrm{min} .)\end{array}$ & $5.5 \pm 1.1$ & $7.1 \pm 2.2$ & $5.5 \pm 1.2$ & $4.0 \pm 2.1$ & $5.6 \pm 1.8$ \\
\hline Per cent arterial glucose extracted & 10.4 & 9.0 & 6.7 & 5.6 & 7.3 \\
\hline $\begin{array}{l}\text { Arterial lactate content } \\
\quad(\mathrm{mg} . / 100 \mathrm{ml} .)\end{array}$ & $5.9 \pm 2.0$ & $9.6 \pm 4.2$ & $11.6 \pm 4.8$ & $13.3 \pm 4.5$ & $12.2 \pm 3.1$ \\
\hline $\begin{array}{l}\text { Cerebral A-V lactate difference } \\
(\mathrm{mg} . / 100 \mathrm{ml} . \text { blood })\end{array}$ & $-0.5 \pm 0.9$ & $0.6 \pm 1.3$ & $0.5 \pm 0.3$ & $-0.2 \pm 0.8$ & $0.4 \pm 1.0$ \\
\hline $\begin{array}{l}\text { Cerebral lactate extracted } \\
(\mathrm{mg} . / 100 \mathrm{Gm} . \text { brain/min.) }\end{array}$ & $-0.23 \pm 0.37$ & $0.36 \pm 0.19$ & $0.29 \pm 0.16$ & $-0.08 \pm 0.43$ & $0.15 \pm 0.37$ \\
\hline $\begin{array}{l}\text { Arterial pyruvate content } \\
(\mathrm{mg} . / 100 \mathrm{ml} . \mathrm{blood} / \mathrm{min} .)\end{array}$ & $1.06 \pm 0.32$ & $1.74 \pm 0.82$ & $2.11 \pm 0.63$ & $2.25 \pm 0.52$ & $2.22 \pm 0.47$ \\
\hline $\begin{array}{l}\text { Cerebral A-V pyruvate difference } \\
\text { (mg./100 ml. blood) }\end{array}$ & $-0.06 \pm 0.11$ & $0.14 \pm 0.21$ & $0.16 \pm 0.08$ & $0.15 \pm 0.23$ & $0.24 \pm 0.08$ \\
\hline Cerebral pyruvate extraction & $-0.31 \pm 0.05$ & $0.09 \pm 0.13$ & $0.09 \pm 0.07$ & $0.09 \pm 0.12$ & $0.13 \pm 0.06$ \\
\hline
\end{tabular}

* Standard deviation (in each case).

$\dagger$ Arteriovenous. 

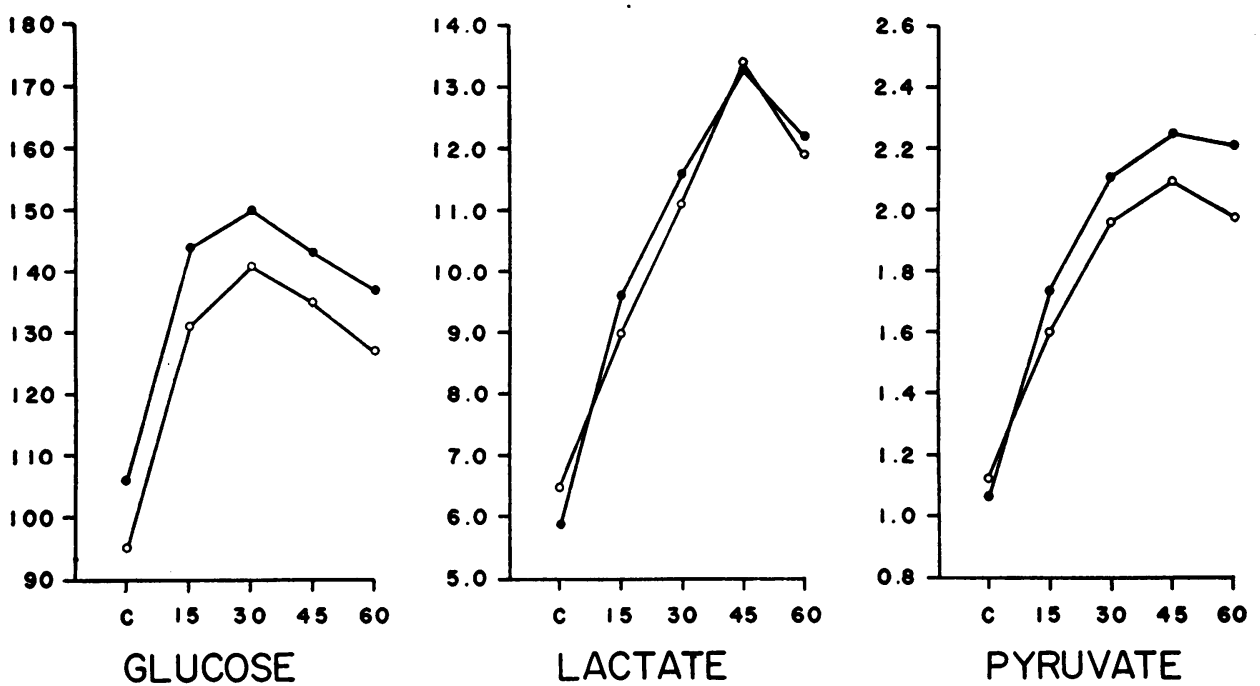

$\longrightarrow$ ARTERIAL - VENOUS

Fig. 1. Mean Arterial and Internal Jugular Blood Content of Glucose, Lactate and Pyruvate for Eight Subjects

Values are plotted at the control determination (C) and at each 15 minute interval throughout the ensuing hour. The vertical scale is expressed in milligrams per 100 milliliters of blood.

\section{DISCUSSION}

Previous reports of brain glucose, lactate and pyruvate extraction in the fasting state agree reasonably well with those reported here and indicate that, whereas glucose is taken up by the brain in the fasting state, both lactate and pyruvate are given up to the perfusing blood $(9,10)$. Postprandially, however, the state changes, with glucose consumption fluctuating above and below the control values, and lactate uptake fluctuating above the fasting level, while pyruvate was taken up consistently by the brain and in amounts which correlated directly with the arterial pyruvate level $(\mathrm{r}=0.70, \mathrm{p}<0.001)$ (see Table II).

Contrary to the behavior of peripheral tissues $(1-4)$ the brain extracts roughly the same quantity of glucose in the fasting state as it does during the peak of the arterial concentration of glucose after a test meal. The percentage of glucose extracted decreases as the arterial blood glucose content rises and the calculated amount of glucose taken up by the brain varies, indicating a transient increase as the level rises and a compensatory decrease as the arterial level falls. Overall, there was no correlation between the arterial glucose level and either the arteriovenous dif- ference across the brain $(r=0.03)$ or the glucose consumption of the brain $(r=0.08)$. These observations are consistent with Gey's report of a very low concentration of glucose in the brain (11) and the hypothesis that the blood to brain gradient of glucose is great enough at all times during physiological conditions for the brain cells to extract what glucose they need. The sustained glucose uptake by the brain and the relative independence of this uptake from the arterial level are also in line with studies of Morgan and Park on the glucose transport into the heart muscle (12). These workers concluded that a transport mechanism rather than simple diffusion explained glucose entrance into the heart muscle cell, since the rate of uptake was not related linearly to the gradient of glucose across the membrane and since there was competitive inhibition of glucose transport by high concentrations of arabinose. If a transport mechanism accepted the major portion of glucose extracted by the brain, but there was transient passive diffusion of glucose into the brain or its interstices during the time that blood sugar rises rapidly, the excess of glucose taken up by the brain during the increase in arterial blood sugar might be expected to be utilized dur- 
ing the time when blood sugar fell again to normal. From data concerning glycogen content of the dog .brain it has been extrapolated that the human brain contains $1.5 \mathrm{Gm}$. glycogen (13), hence some storage of glucose seems reasonably certain.

Comparison of the calculated cerebral oxygen consumption and the quantity of oxygen required for complete oxidation of the glucose taken up by the brain (corrected by subtracting the glucose equivalent of the lactate and pyruvate given up to the blood stream by the brain) indicates that in the fasting state the measured oxygen consumption constitutes 88 per cent of that which would theoretically be required. This differs by 12 per cent from the theoretical complete stoichiometric relations found through similar calculations by Himwich and Himwich (10) and may well be due to experimental error.

The theoretical oxygen consumption, as calculated considering carbohydrate taken up and released at each 15 minute interval, averaged 80 per cent of the oxygen consumption calculated through multiplying the arteriovenous oxygen difference across the brain by cerebral blood flow, although fluctuations from 60 to 117 per cent occurred at the lowest and highest points. The data would fit with the hypothesis that the cerebral metabolism of carbohydrate remains essentially unchanged throughout, but that there is transitory carbohydrate accumulation during a time of rising blood level and that this tends to be utilized during the time when the blood carbohydrate level is falling sharply. The fact that these adjustments fluctuated above and below but returned to their control state at the end of one hour seems to deny their relation to hunger and is compatible with Stunkard's report of cessation of hunger contractions in a decerebrate man after glucose administration (14). Furthermore, it seems probable from brain-destructive lesions in experimental animals, produced by gold thioglucose, that the "hunger center" itself may actually be a very small portion of the ventromedial hypothalamus $(15,16)$. A considerable variation in the quantity of glucose consumed by such a small center might be physiologically important, yet not demonstrable in such gross metabolic measurements as the carbohydrate consumption of the brain as a whole.

\section{CONCLUSIONS}

1. A group of eight human subjects has been studied by determination of cerebral blood flow and brain carbohydrate uptake before and after a test meal.

2. During the time when the arterial level of glucose, lactate and pyruvate was rising, the brain took up larger quantities of these carbohydrates. As the peak blood concentration of glucose was reached the uptake returned to the control values, and during the time when the level of the substances was falling rapidly, uptake of glucose by the brain was reduced to below the control value.

3. The fact that glucose and lactate uptake are not related to their absolute arterial level is compatible with the thesis that the arterial level of these substances does not control their rate of utilization by the brain.

4. Brain pyruvate extraction and calculated consumption were correlated directly with the arterial level of pyruvate.

\section{REFERENCES}

1. Van Itallie, T. B., Beaudoin, R., and Mayer, J. Arteriovenous glucose differences, metabolic hypoglycemia and food intake in man. Amer. J. clin. Nutr. 1953, 1, 208.

2. Stunkard, A. J., and Wolff, H. G. Studies on the physiology of hunger. I. The effect of intravenous administration of glucose on gastric hunger contractions in man. J. clin. Invest. 1956, 35, 954.

3. Mayer, J. The physiologic basis of obesity and leanness, Part I and Part II. Nutr. Abstr. Rev. 1955, 25, 597 and 871.

4. Mayer, J. Hunger and the hypothalamus. Clin. Res. 1957, 5, 123.

5. Folin, O., and Malmros, H. An improved form of Folin's micro-method for blood glucose determination. J. biol . Chem. 1929, 83, 115.

6. Friedemann, T. E., and Haugen, G. E. Pyruvic acid II. The determination of ketoacids in blood and urine. J. biol. Chem. 1943, 147, 415.

7. Barker, S. B., and Summerson, W. H. The colorimetric determination of lactic acid in biological material. J. biol. Chem. 1941, 138, 535.

8. Kety, S. S., and Schmidt, C. F. The determination of cerebral blood flow in man by use of nitrous oxide in low concentrations. Amer. J. Physiol. 1945, 143, 53. 
9. Himwich, H. E. Brain Metabolism and Cerebral Disorders. Baltimore, The Williams and Wilkins Co., 1951, p. 24.

10. Himwich, W. A., and Himwich, H. E. Pyruvic acid exchange of the brain. J. Neurophysiol. 1946, 9, 133.

11. Gey, K. F. The concentration of glucose in rat tissues. Biochem. J. 1956, 64, 145.

12. Morgan, H. E., and Park, C. R. Sugar transport across muscle cell membrane. Fed. Proc. 1958, 17, 278.

13. Himwich, H. E., Bowman, K. M., Wortis, J., and Fazekas, J. F. Biochemical changes occurring in the cerebral blood during the insulin treatment of schizophrenia. J. nerv. ment. Dis. 1939, 89, 273.

14. Stunkard, A. Studies on the physiology of hunger. II. The effect of the intravenous administration of various nutrients on the gastric hunger contractions of a man with severe brain damage. Amer. J. clin. Nutr. 1957, 5, 203.

15. Marshall, N. B., Barrnett, R. J., and Mayer, J. Hypothalamic lesions in gold thioglucose injected mice. Proc. Soc. exp. Biol. (N. Y.) 1955, 90, 240.

16. Mayer, J., and Marshall, N. B. Specificity of gold thioglucose for ventromedial hypothalamic lesions and hyperphagia. Nature (Lond.) 1956, 178, 1399. 